\title{
Fuzzy DEMATEL analysis of barriers to Blockchain-based life cycle assessment in China
}

\author{
Muhammad Farooque ${ }^{\mathrm{a}}$, Vipul Jain ${ }^{\mathrm{b}}$, Abraham Zhang ${ }^{\mathrm{c}}$, Zhi Li ${ }^{\mathrm{d}, *}$ \\ ${ }^{a}$ Sukkur IBA University, Sukkur, Pakistan \\ ${ }^{\mathrm{b}}$ School of Management, Wellington School of Business and Government, Victoria University of Wellington, 23, Lambton Quay, Pipitea Campus, PO Box 600, Wellington \\ 6140 , New Zealand \\ ${ }^{\mathrm{c}}$ Essex Business School, University of Essex, Essex, UK \\ d Guangdong Provincial Key Laboratory of Computer Integrated Manufacturing Systems, School of Electromechanical Engineering, Guangdong University of Technology, \\ Guangzhou, Guangdong 510006, China
}

\section{A R T I C L E I N F O}

\section{Keywords:}

Blockchain

Life cycle assessment

Supply chain sustainability

Barrier

Fuzzy DEMATEL

\begin{abstract}
A B S T R A C T
The emerging Blockchain technology can drastically improve the effectiveness and efficiency of life cycle assessment, which is widely used for assessing the environmental impact of products and processes. However, Blockchain adoption is impeded by various barriers including systems-related, external, intra-organizational and inter-organizational barriers. So far, no research has analyzed how these barriers interact with each other for better decision-making in life cycle assessment. This research narrows the knowledge gap by prioritizing the important barriers using a fuzzy Decision-Making Trial and Evaluation of Laboratory (DEMATEL) method. Pairwise comparison data were collected from three representative organizations in China, which all have Blockchain implementation experiences. The results show that the key cause barriers are immaturity of technology, and technical challenges for collecting supply chain data in real time. The prominent barriers include lack of new organizational policies for using technology, and lack of government policy/regulation guidance and support, among others. Managerial implications are discussed based on the results and findings.
\end{abstract}

\section{Introduction}

Businesses across the globe are recognizing the importance of integrating environmental sustainability into business practices and making a transition to a circular economy, which offers a new and compelling perspective (Farooque, Zhang, Thürer, Qu, \& Huisingh, 2019). The quest for environmental sustainability has been driven by a variety of supply chain stakeholders including businesses, consumers, government legislation bodies, non-governmental organizations (Carter \& Liane Easton, 2011). Emissions have been a key concern as they have a prolonged impact on the environment and have resulted in many problems including global warming, ozone depletion, climate change and thereby also have an impact on human health and the ecosystem (Rebitzer et al., 2004). Unarguably, global warming and reduction of emissions are prominent matters in framing policies nowadays as they impact ecosystems in different parts of the world (Finnveden et al., 2009; Weidema, Thrane, Christensen, Schmidt, \& Løkke, 2008).

Clearly there is a need to evaluate/measure environmental impact so that necessary measures can be taken to reduce/mitigate the adverse effects. For example, monitoring and controlling $\mathrm{CO}_{2}$ emissions is crucial for combating global warming (Pennington et al., 2004). This explains why environmental impact analysis has gained momentum among researchers in recent years. Among the various tools and techniques available, life cycle assessment (LCA) is one of the most widely used ones for measuring the environmental impact of products and processes. It is popular in both public and private sectors and has developed from energy analysis to impact and costing models to a fully-fledged LCA in the 21st century (Guinée et al., 2011). LCA evaluates the environmental impact of products or services from the cradle to the grave. It is mainly based on the lifecycle side effects of products or services on environmental aspects including pollution, material usage, energy and water consumption, waste generation, etc.

The use of LCA faces some challenges in practice. LCA tools are very data sensitive and a key challenge in LCA applications is data availability (Walter Klöpffer \& Rebitzer, 2000). LCA requires a large amount of data and its collection and compilation are time consuming and difficult. Reporting and exchange of the data is also a tedious task. These challenges are amplified when a business operates across multiple countries (Schmidt \& Sullivan, 2002) as global supply chains are often very fragmented, which makes it a daunting task to track the

\footnotetext{
* Corresponding author.

E-mail addresses: farooq@iba-suk.edu.pk (M. Farooque), Vipul.Jain@vuw.ac.nz (V. Jain), abraham.zhang@essex.ac.uk (A. Zhang), piersli@foxmail.com (Z. Li).
} 
environmental impact throughout the lifecycle of a product. The other key challenge is the integrity of data. Missing data and inaccurate data are common problems in database management. Some organizations may even falsify data to fool the public on their environmental performance (Saberi, Kouhizadeh, Sarkis, \& Shen, 2019).

Blockchain technology offers a promising future to overcome these challenges associated with LCA. Blockchain is a decentralized, distributed and public digital ledger that is used to record transactions across many computers so that any involved record cannot be altered retroactively, without the alteration of all subsequent blocks (Ølnes, Ubacht, \& Janssen, 2017). Blockchain can be characterized with decentralized data bases, information transparency and data security. It has received attention in numerous fields of application including finance, healthcare (Mettler, 2016), and government (Ølnes et al., 2017). Blockchain-based LCA can be aided by internet of things (IoT) and big data analytics (BDA). IoT has the capability to acquire data automatically and efficiently in real time. BDA make it possible to analyze big data for generating insights to aid decision-making. Therefore, Blockchain technology ensures data validity, reliability and transparency, and can reduce information uncertainty, providing better data inputs and outputs for LCA tools. Benefits of Blockchain adoption include less time for LCA data collection, improved data quality, traceability of the data sources, and storage of the environmental information of a product through its lifecycle to better manage its recycling and disposal.

Despite a promising future and vast advantages, Blockchain-based LCA has not attracted much attention. So far, Blockchain applications have been mainly motivated by economic benefits and transparency requirements instead of environmental objectives. Barriers exists to adopting Blockchain for environmental management including LCA. Blockchainbased LCA is still at the conceptualization (Zhang, Zhong, Farooque, Kang, \& Venkatesh, 2020) and pilot stage (Liu et al., 2020). This research becomes highly significant as it is timely in advancing the field by identifying and prioritizing the key barriers to the adoption of Blockchain for LCA. More specifically, this study aims to narrow the knowledge gap by investigating the barriers to Blockchain-based LCA in China, the world's largest developing country that faces tremendous challenges in environmental management. This study has the following research objectives:

\section{- To identify the key barriers to adopting Blockchain technology for LCA in China \\ - To investigate how the key barriers interact.}

This study makes a novel contribution by identifying the important barriers based on the extant literature allied with expert inputs. It further employs a fuzzy Decision-Making Trial and Evaluation of Laboratory (DEMATEL) method to prioritize the important barriers to Blockchain-based LCA. DEMATEL originated from the Geneva Research Centre of the Battelle Memorial Institute for examining the causal effect relationships among factors (Fontela \& Gabus, 1976). The prioritization of identified barriers using DEMATEL provides a systematic way to analyze how to circumvent the barriers. Therefore, the study findings aim to assist policy makers and practitioners to develop effective strategies, improving the utilization of Blockchain-based LCA to improve environmental performance. They are not only relevant to the Chinese context but also to other regions which face similar challenges in adopting Blockchain for environmental sustainability.

The remainder of the paper is organized as follows. Section 2 reviews relevant literature. Section 3 explains the methodology and data collection procedures. Section 4 presents results, analysis and findings. Section 5 discusses managerial implications. Section 6 concludes the research, highlighting limitations and directions for future research.

\section{Literature review}

The researchers attempted a systematic literature review of the works at the intersection of Blockchain technology and LCA. A query was made in the Scopus database by using the keywords "Blockchain" and "Life cycle". A total of 99 publications were returned on the search date of 3rd February 2020. Only two publications were identified as directly relevant to the adoption of Blockchain for LCA after the researchers had screened all 99 publications by reading their titles and abstracts. Both of the directly relevant publications (Liu et al., 2020; Zhang et al., 2020) are conceptual in nature, showing the research topic is at a nascent stage. The following literature review focuses on the LCA and barrier study techniques.

\subsection{Life cycle assessment}

Life cycle assessment measures the impacts of a product on the environment throughout its entire lifecycle including extraction of raw materials, production, distribution, consumption and usage of the products, and finally product disposal. The main objective of LCA is to identify and quantify both the generated waste and required energy and raw materials in the whole lifecycle while considering their impacts on the environment.

LCA has four main steps: 1) Goal and scope definition, 2) Life Cycle Inventory, 3) Life Cycle Impact Assessment, and 4) Life Cycle Interpretation (Rebitzer et al., 2004). The first step aims to define how big a part of the product life cycle will be taken in assessment and what end the assessment will be serving. Inventory analysis describes material and energy flows within the product system and especially its interaction with the environment, consumed raw materials, and emissions to the environment. Details from inventory analysis serve for impact assessment in the third step. Finally, interpretation of a life cycle involves the critical review, determination of data sensitivity, and result presentation. As a well-established tool, LCA is covered by a series of international standards set by the International Standardization Organization (ISO). They include ISO14040 (LCA-Principals and guidelines), ISO14041 (LCA-Life Inventory Analysis), ISO14042 (LCA-Impact Assessment), and ISO14043 (LCA-Interpretation) which are in line with the four steps of LCA.

Besides the standard LCA procedures stipulated by the ISO, many variants of LCA are used in practice depending on organizational needs. Generally speaking, LCA methods have received approval for logical consistency and thoroughness but have been criticized for requiring too much data, money and time when each is in short supply. At AT\&T researchers have developed qualitative expert opinion with qualitative data of environment which generate quantitative results apart from the justification of LCA uncertainty and multidimensionality. This method is called Abridged Life Cycle Assessment (Wernick \& Ausubel, 1997). In addition, in a transition to a circular economy (Farooque, Zhang, Thürer, et al., 2019), it is necessary to revise LCA-ISO standards from a "cradleto-grave" to a "cradle-to-cradle" concept. The principle of extended producer responsibility (Krishna, Manickam, Shah, \& Davergave, 2017) also has implications for the development of the LCA method.

\subsection{Barrier study techniques}

Various multi-criteria decision-making techniques have been used in barrier studies. In the context of the sustainable supply chain management, DEMATEL, Interpretive Structural Modelling (ISM), and Analytical Hierarchy Process (AHP) methods are the most commonly used techniques (Farooque, Zhang, \& Liu, 2019; Mangla et al., 2018). Analytic hierarchy process (AHP) has been widely used due to its simplicity but it is not capable of analyzing the complicated interdependencies among factors. DEMATEL and ISM are found to have an edge over AHP due to their usefulness in capturing interdependencies (Mangla et al., 2018).

Both the ISM and DEMATEL techniques are powerful structural modeling tools which can be used for the hierarchical representation of the factors. In ISM, the factors are categorized in four possible hierarchies, whereas in the DEMATEL the intensity of influence is captured on a Likert scale (e.g., 0-4). Comparing DEMATEL and ISM, DEMATEL is more advantageous because it provides the degree of influence of the factors (Alam-Tabriz, Rajabani, \& Farrokh, 2014) and uses heterogeneous factors for the analysis (Herrera-Viedma, 2015). Furthermore, 
Table 1

A comparison of DEMATEL, ISM and AHP.

\begin{tabular}{|c|c|c|}
\hline DEMATEL & ISM & AHP \\
\hline $\begin{array}{l}\text { DEMATEL helps to uncover the causal interactions among } \\
\text { the variables based on their cause and effect groups. } \\
\text { Relatively micro-oriented. Visualizes causal } \\
\text { relationships through impact-relations maps. }\end{array}$ & $\begin{array}{l}\text { ISM uncovers the contextual interactions among } \\
\text { variables based on their driving potential and } \\
\text { dependencies. Macro-oriented. Breaks down complex } \\
\text { systems into sub-systems. }\end{array}$ & $\begin{array}{l}\text { AHP does not provide any interdependencies between } \\
\text { and among the variables, but is rather used to draw the } \\
\text { hierarchical structure of the variables. }\end{array}$ \\
\hline
\end{tabular}

Source: Adopted from Farooque, Zhang, and Liu (2019).

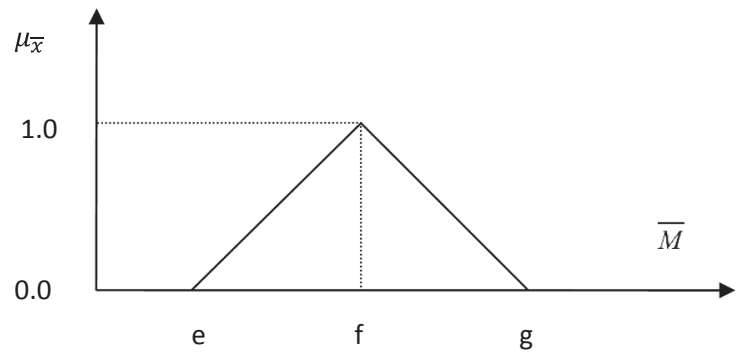

Fig. 1. Triangular fuzzy numbers.

ISM is a macro-oriented approach which breaks down complex systems into sub-systems (Kumar \& Dixit, 2018), whereas DEMATEL is relatively micro-oriented. It quantifies the intensity of direct and indirect relationships among factors and visualizes causal relationships through impact-relations maps (Kumar \& Dixit, 2018). Thus, DEMATEL was found to be more suitable than ISM for this study.

Table 1 summarizes a comparison of DEMATEL, ISM and AHP. Farooque, Zhang, and Liu (2019) conducted a very comprehensive comparison of the most widely-used multi-criteria decision-making techniques. They also recommended DEMATEL as being most suitable for barrier studies. Considering biases and fuzziness in man-made decisions/evaluation, fuzzy set theory was used to extend the standard DEMATEL approach to Fuzzy DEMATEL (Wu \& Lee, 2007; Wu, 2012).

DEMATEL and Fuzzy DEMATEL have been utilized for studying problems in operations and supply chain management, for example, procurement (Dou, Sarkis, \& Bai, 2014), supply chain integration (Awasthi \& Grzybowska, 2014), and dental services (Bahadori, Ravangard, \& Asghari, 2013). They have also been used for prioritizing the barriers in sustainability-related issues including green supplier selection (Büyüiközkan \& Çifçi, 2012), implementing RoHS regulations (Dou \& Sarkis, 2013), automotive parts re-manufacturing (Xia, Govindan, \& Zhu, 2015), and green supply practices (Wu, Liao, Tseng, \& Chiu, 2015). Also, Zhu, Sarkis, and Lai (2015) used grey-based DEMATEL in studying the supply chain-related barriers at strategic and operational levels. Recently, Venkatesh et al. (2017) used Fuzzy DEMATEL for studying barriers in coastal shipping development as a sustainable and efficient alternative to road transport in India. (Farooque, Zhang, \& Liu, 2019) used Fuzzy DEMATEL to systematically analyze and prioritize barriers to circular food supply chains in China. In a nutshell, the Fuzzy DEMATEL approach is used for analyzing the causal-effect relationships among various factors that are interdependent in nature. The analysis makes use of pairwise comparison data sets and calculates the degree of influence among factors.

\section{Methodology and data}

\subsection{Fuzzy DEMATEL}

This study used fuzzy DEMATEL, a fuzzy set extension to the standard DEMATEL technique. As mentioned earlier, Fuzzy DEMATEL can handle the inherent biases and vagueness in human judgments (Lin, 2013; Wu \& Lee, 2007). The researchers followed the six steps specified in Venkatesh et al. (2017) to analyze the barriers to adopting Blockchain for LCA in China.

Step 1: Surveying the research participants to construct a pairwise comparison matrix

In this step, each participant was asked to assess the impact barrier $i$ has on barrier $j$ on a scale from 0 to 4 ( 0 means no effect; $1-4$ means the degree of influence from small to large).

Step 2: Obtaining the fuzzy initial direct relation matrix (A)

Triangular fuzzy numbers (TFNs) were used to capture the fuzziness in the judgments (Seçme, Bayrakdaroğlu, \& Kahraman, 2009). Each TFN was expressed as a triplet (e, f, g) to explain a fuzzy event. The parameters e, $f$, and $g$ specified the smallest possible, the most promising, and the largest possible value respectively. A triangular fuzzy number $\tilde{\mathrm{M}}$ from universe of discourse to [0,1] is shown in Fig. 1 (Deng, 1999).

Table 2 shows the fuzzy linguistic scale used (Venkatesh et al., 2017; Wu \& Lee, 2007) to convert impact scores to triangular fuzzy numbers.

Suppose $x_{i j}^{k}=e_{i j}^{k}, f_{i j}^{k}, g_{i j}^{k}$ where $1 \leq k \leq K$ is to be the fuzzy evaluation that the $\mathrm{k}^{\text {th }}$ research participant rate on the degree to which barrier $i$ impacts barrier $j$. If ' $\mathrm{K}$ ' is the number of participants who estimated causality between the identified $\mathrm{n}$ barriers, then inputs given by the participants result in an $\mathrm{n} \times \mathrm{n}$ matrix, i.e. $X^{k}=x_{i j}^{k}$; where $\mathrm{k}=1,2,34 \ldots \mathrm{n}$ (number of research participants).

$a_{i j}=\frac{1}{k \sum x \mathrm{kij}}$

After that, the defuzzification process converted the fuzzy numbers to crisp numbers to make it possible to carry out matrix operations. Eq. (2) was used for defuzzifying the fuzzy direct relation matrix:

$\mathrm{I}_{\mathrm{T}}=\frac{1}{6}(e+4 f+g)$

Step 3: Constructing the normalized initial direct relation matrix (D)

$\mathrm{m}=\min \left[\frac{1}{\max \sum_{\mathrm{j}=1}^{\mathrm{n}}\left|\mathrm{a}_{\mathrm{ij}}\right|}, \frac{1}{\max \sum_{\mathrm{i}=1}^{\mathrm{n}}\left|\mathrm{a}_{\mathrm{ij}}\right|}\right]$

$\mathrm{D}=\mathrm{m} \times \mathrm{A}$

Step 4: Obtaining the total relation matrix

$\mathrm{T}=(\mathrm{I}-\mathrm{D})^{-1}$

Where I: Identity matrix; T: Total relation matrix

$\mathrm{T}=\left[\mathrm{t}_{\mathrm{ij}}\right]_{\mathrm{n} \times \mathrm{n}}$

Step 5: Calculating the sum of rows (R) and the sum of columns (C)

$R=\left[\sum_{j=1}^{n} t_{i j}\right]_{n \times 1}$

Table 2

Fuzzy linguistic scale.

\begin{tabular}{lll}
\hline Impact score & $\begin{array}{l}\text { Description of linguistic } \\
\text { variable }\end{array}$ & $\begin{array}{l}\text { Equivalent triangular fuzzy } \\
\text { numbers }\end{array}$ \\
\hline 0 & No influence (No) & $(0,0,0.25)$ \\
1 & Very low influence (VL) & $(0,0.25,0.5)$ \\
2 & Low influence (L) & $(0.25,0.5,0.75)$ \\
3 & High influence (H) & $(0.5,0.75,1.0)$ \\
4 & Very high influence (VH) & $(0.75,1.0,1.0)$ \\
\hline
\end{tabular}


$\mathrm{C}=\left[\sum_{\mathrm{i}=1}^{\mathrm{n}} \mathrm{t}_{\mathrm{ij}}\right]_{1 \times \mathrm{n}}$

$\mathrm{R}$ represents the overall impact that barrier $i$ has on barrier $j$. C stands for the overall effect experienced by barrier $i$ from barrier $j$.

Step 6: Creating the cause-effect diagram

A cause-effect diagram was created using the data set of $(R+C ; R-C)$. $(\mathrm{R}+\mathrm{C})$ is the horizontal axis which measures the prominence of a barrier, indicating its total effects in terms of influenced and influential power. $(\mathrm{R}-\mathrm{C})$ is the vertical axis which explains the causal-effect relationship between the barriers. A barrier falls into the cause group if its $(\mathrm{R}-\mathrm{C})$ value is greater than zero. Conversely, a barrier falls into the effect group if its (R-C) value is smaller than zero (Lin, 2013; Wu, 2012). Furthermore, significant relationships between barriers were mapped on the cause-effect diagram by arrows to highlight their interdependence.

\subsection{Data}

\subsubsection{Barriers to adopting Blockchain for life cycle assessment in China}

Through an extensive review of literature, Saberi et al. (2019) identified a very comprehensive list of 22 generic barriers to adopting
Blockchain for sustainable supply chain management. Based on this list, the researchers shortlisted the most relevant barriers to adopting Blockchain for LCA in China. Table 3 provides details on the process of shortlisting barriers which are most relevant to barriers to Blockchainbased LCA in China. Some of the barriers identified by Saberi et al. (2019) were excluded from the shortlist because they are less relevant to LCA. Several closely interrelated barriers were combined. Given that China does not have a strong culture of environmental protection, the researchers added "lack of a culture of environmental protection" (Farooque, Zhang, \& Liu, 2019; Zhang et al., 2019) as a barrier, to take into consideration the cultural context.

In the process of shortlisting the barriers to Blockchain-based LCA, the researchers sought feedback from two senior business managers who have experience in Blockchain implementation in China. It was found that the original description of Saberi et al. (2019) on several barriers was ambiguous and was likely to cause misunderstanding in the Chinese business context. Therefore, some minor revisions in wording were made to their original description of barriers (Saberi et al., 2019) to improve clarity to ensure content validity. The resulting final list of 13 barriers in four categories is provided in the last column of Table 3.

Table 3

Shortlisting barriers to Blockchain-based LCA in China.

\begin{tabular}{|c|c|c|c|c|}
\hline Barrier category & $\mathrm{S} / \mathrm{N}$ & General barriers for adopting Blockchain & Shortlisting decision and explanation & $\begin{array}{l}\text { Specific barriers to adopting } \\
\text { Blockchain for LCA in China }\end{array}$ \\
\hline \multirow[t]{7}{*}{$\begin{array}{l}\text { Intra-organizational } \\
\quad \text { barriers }\end{array}$} & 1 & Financial constraints & $\begin{array}{l}\text { Exclude - largely dependent on barrier } \\
\# 2\end{array}$ & \multirow{7}{*}{$\begin{array}{l}\text { B1: Hesitation to convert to new } \\
\text { systems } \\
\text { B2: Lack of management commitment } \\
\text { and support } \\
\text { B3: Lack of new organizational } \\
\text { policies for using technology }\end{array}$} \\
\hline & 2 & $\begin{array}{l}\text { Lack of management commitment and } \\
\text { support }\end{array}$ & Include - very important & \\
\hline & 3 & $\begin{array}{l}\text { Lack of new organizational policies for using } \\
\text { technology }\end{array}$ & Include - a key challenge & \\
\hline & 4 & Lack of knowledge and expertise & $\begin{array}{l}\text { Exclude - technology providers are } \\
\text { available in China }\end{array}$ & \\
\hline & 5 & Difficulty in changing organizational culture & Exclude - less relevant to LCA & \\
\hline & 6 & Hesitation to convert to new systems & $\begin{array}{l}\text { Include - need to be combined with } \\
\text { barrier } \# 15\end{array}$ & \\
\hline & 7 & $\begin{array}{l}\text { Lack of tools for Blockchain technology } \\
\text { implementation in sustainable supply chains }\end{array}$ & $\begin{array}{l}\text { Exclude - less relevant to LCA } \\
\text { implementation }\end{array}$ & \\
\hline \multirow[t]{5}{*}{$\begin{array}{l}\text { Inter-organizational } \\
\quad \text { barriers }\end{array}$} & 8 & $\begin{array}{l}\text { Lack of customer awareness and tendency } \\
\text { about sustainability and Blockchain } \\
\text { technology }\end{array}$ & $\begin{array}{l}\text { Exclude - less relevant to LCA } \\
\text { implementation }\end{array}$ & \multirow{5}{*}{$\begin{array}{l}\text { B4: Problems in collaboration, } \\
\text { communication and coordination in } \\
\text { the supply chain } \\
\text { B5: Challenge of information } \\
\text { disclosure policy between partners in } \\
\text { the supply chain } \\
\text { B6: Challenges in integrating } \\
\text { sustainable practices and Blockchain } \\
\text { technology through supply chain } \\
\text { management (SCM) }\end{array}$} \\
\hline & 9 & $\begin{array}{l}\text { Problems in collaboration, communication } \\
\text { and coordination in the supply chain }\end{array}$ & Include - important & \\
\hline & 10 & $\begin{array}{l}\text { Challenge of information disclosure policy } \\
\text { between partners in the supply chain }\end{array}$ & Include - a key challenge & \\
\hline & 11 & $\begin{array}{l}\text { Challenges in integrating sustainable } \\
\text { practices and Blockchain technology through } \\
\text { SCM }\end{array}$ & Include - a key challenge & \\
\hline & 12 & Cultural differences of supply chain partners & Exclude - less relevant to LCA in China & \\
\hline \multirow[t]{5}{*}{ System-related barriers } & 13 & Security challenge & Include - a key challenge & \multirow{5}{*}{$\begin{array}{l}\text { B7: Immaturity of technology } \\
\text { B8: Security challenge } \\
\text { B9: Doubt about Blockchain } \\
\text { technology due to negative public } \\
\text { perception } \\
\text { B10: Technical challenges for } \\
\text { collecting supply chain data in real } \\
\text { time }\end{array}$} \\
\hline & 14 & Access to technology & $\begin{array}{l}\text { Include - need to be rephrased to } \\
\text { improve clarity }\end{array}$ & \\
\hline & 15 & $\begin{array}{l}\text { Hesitation to adopt Blockchain technology, } \\
\text { due to negative public perception }\end{array}$ & $\begin{array}{l}\text { Include - need to be merged into barrier } \\
\# 6 \text {. }\end{array}$ & \\
\hline & 16 & $\begin{array}{l}\text { Immutability challenge of Blockchain } \\
\text { technology }\end{array}$ & $\begin{array}{l}\text { Exclude - no longer a major technical } \\
\text { challenge }\end{array}$ & \\
\hline & 17 & Immaturity of technology & $\begin{array}{l}\text { Include - the emerging nature of the } \\
\text { Blockchain technology }\end{array}$ & \\
\hline \multirow[t]{5}{*}{ External barriers } & 18 & Lack of governmental policies & $\begin{array}{l}\text { Include - need to be combined with } \\
\text { barrier } \# 22\end{array}$ & \multirow{5}{*}{$\begin{array}{l}\text { B11: Lack of governmental policy/ } \\
\text { regulation guidance and support } \\
\text { B12: Lack of a culture of } \\
\text { environmental protection } \\
\text { B13: Lack of external stakeholder } \\
\text { pressure and involvement }\end{array}$} \\
\hline & 19 & Market competition and uncertainty & Exclude - less relevant to LCA & \\
\hline & 20 & Lack of external stakeholder involvement & $\begin{array}{l}\text { Include - need to be rephrased to } \\
\text { improve clarity }\end{array}$ & \\
\hline & 21 & $\begin{array}{l}\text { Lack of industry involvement in ethical and } \\
\text { safe practices }\end{array}$ & $\begin{array}{l}\text { Exclude - less relevant due to the } \\
\text { existence of industry-wide standards on } \\
\text { LCA }\end{array}$ & \\
\hline & 22 & $\begin{array}{l}\text { Lack of rewards and encouragement } \\
\text { programs }\end{array}$ & $\begin{array}{l}\text { Include - need to be combined with } \\
\text { barrier } \# 18\end{array}$ & \\
\hline
\end{tabular}




\subsubsection{Data collection procedures}

The data required for DEMATEL analysis were collected in China using the Mandarin Chinese language. The list of barriers presented above was first developed in English, and then translated into Chinese by two experienced researchers who are bilingual. A matrix form including the barriers was provided to research participants to make pairwise comparison of barriers and rate their causal-effect relationships on each other (Venkatesh et al., 2017). The research participants were also required to rank the barriers by their perceived order of importance from 1 to 13 , with 1 representing the most important and 13 being the least important.

To ensure data quality, the researchers used their professional networks to approach potential participants who had multiple years of experience with Blockchain technology. Participation in the research was voluntary. The research participants were assured of the confidentiality of their data and their use for academic research purposes only. The initial plan was to survey 30 participants. However, the target sample size was found to be unrealistic because very few organizations in China have implemented Blockchain or are seriously evaluating Blockchain-based systems for their business use. There has been hype around Blockchain technology in the market, but most businesses have a wait-and-see attitude for potential implementation.

After overcoming some difficulties, the researchers eventually secured face-to-face meetings to obtain pairwise comparison data from three representative stakeholders who are knowledgeable on the topic. Their organizations are: 1) A technology provider based in Guangdong province, which was an early mover in the Blockchain technology market in China and which had started in 2016 to research and develop Blockchain-based solutions; 2) A large manufacturer based in Beijing, which designs and manufactures control equipment and engineering systems; 3) A large retailer headquartered in Jiangsu province, which sells pharmaceutical products through a network of retail outlets in China. The profile of the participants is presented in Appendix A.

It is apparent that these three organizations have different interests in the implementation of Blockchain-based LCA in China. The technology provider's main interest is in overcoming technical challenges and winning contracts with potential clients. The manufacturer is mostly concerned about the environmental footprint of its production activities because they are the main sources of emissions. The retailer's concern is likely to be on the logistics and supply chain activities as it does not manufacture goods. Using data from multiple types of stakeholders helps ensure the robustness of the analysis and results (Zhang et al., 2019).

\section{Results, analysis and findings}

The following section presents DEMATEL results (net cause-effect values, evaluators' importance rankings, and DEMATEL-based rankings) and the prominence-causal relationship diagrams for all three study evaluators (i.e., technology provider, manufacturer and retailer). The total relation matrix for each evaluator is presented in Appendix B, $\mathrm{C}$ and D respectively. We only mapped significant relationships (highlighted as bold values) above a threshold value ( $\varnothing$ ) calculated by adding 1.5 standard deviations to the mean of the total relation matrix (T) as a benchmark following Li and Tzeng (2009). These significant relationships are also plotted in Figs. 2-4.

\subsection{Fuzzy DEMATEL results of the technology provider}

Table 4 and Fig. 2 show the DEMATEL results of the first evaluator who is a technology provider. Lack of government policy/regulation guidance and support (B11), immaturity of technology (B7), lack of external stakeholder pressure and involvement (B13), security challenges (B8), lack of a culture of environmental protection (B12) and lack of new organizational policies for using technology (B3) are identified as the cause barriers from the technology provider's perspective. However, by looking at the interrelationships of the barriers presented in Fig. 2 and the DEMATEL results (Table 4), B11, B7 and B13 clearly appear to be the key cause barriers affecting B1, B2, B3 and B6 respectively. Similarly, B13 and B11 have a high R + C score, suggesting these as the most influential barriers to Blockchain-based LCA from a technology provider perspective.

\subsection{Fuzzy DEMATEL results of the manufacturer}

Table 5 and Fig. 3 show the DEMATEL results of the second evaluator who is a manufacturer. Technical challenges for collecting supply chain data in real time (B10), immaturity of technology (B7), challenge of information disclosure policy between partners in the supply chain (B5), doubt about Blockchain technology due to negative public perception (B9), challenges in integrating sustainable practices and Blockchain technology through SCM (B6), lack of management commitment and support (B2) and lack of new organizational policies for using technology (B3) are identified as the cause barriers from the manufacturer's perspective. However, by looking at the interrelationships of the barriers presented in Fig. 3 and DEMATEL results (Table 5), B10 is identified as the most significant cause barrier followed by B7 which affects barriers B3 and B4 (i.e., the most prominent barriers from the manufacturer's perspective).

\subsection{Fuzzy DEMATEL results of the retailer}

Table 6 and Fig. 4 show the DEMATEL results of the second evaluator who is a retailer. Immaturity of technology (B7), technical challenges for collecting supply chain data in real time (B10), lack of new organizational policies for using technology (B3), problems in collaboration, communication and coordination in the supply chain (B4), security challenges (B8) and challenge of information disclosure policy between partners in the supply chain (B5) are identified as the most significant cause barriers from the retailer's perspective. However, by looking at the interrelationships of the barriers presented in Fig. 4 and DEMATEL results (Table 6), B7, B10, and B3 clearly appear to be the key cause barriers affecting B1, B2, B5, B9, B11 and B13 respectively. Similarly, B3 has the highest $\mathrm{R}+\mathrm{C}$ score suggesting it as the most influential barriers to Blockchain-based LCA from the retailer's perspective.

\subsection{Summary of findings}

Barriers with the highest net causal-effect $(R-C)$ values have the greatest long-term impact on the whole system, so they should be paid more attention. Similarly, the barriers with the highest prominence values have the potential to affect and/or be affected by other barriers and, therefore, managers and policy makers should prioritize addressing or circumventing these in the short run.

Table 7 summarizes the overall results and provides a comparison of key cause and high prominence barriers. The disparities in the results on key cause and high prominence barriers across the three evaluators is quite logical given the differences in the extent of challenges faced by each supply chain entity. For example, technical challenges for collecting supply chain data in real time (B10) are identified as the key cause barriers by both the manufacturer and the retailer (technology users). For them, it is among their core responsibilities to collect real time supply chain data, and technical challenges/interruptions may result in loss of valuable data. However, for technology providers, challenges in integrating sustainable practices and Blockchain technology through SCM (B6) seems to be more of a concern from the technical systems integration viewpoint.

Similarly, lack of new organizational policies for using technology (B3) is identified as a key cause barrier by the retailer only but at the same time it is also a prominent barrier in the case of both the manufacturer and retailer. It makes sense that clear organizational policies 


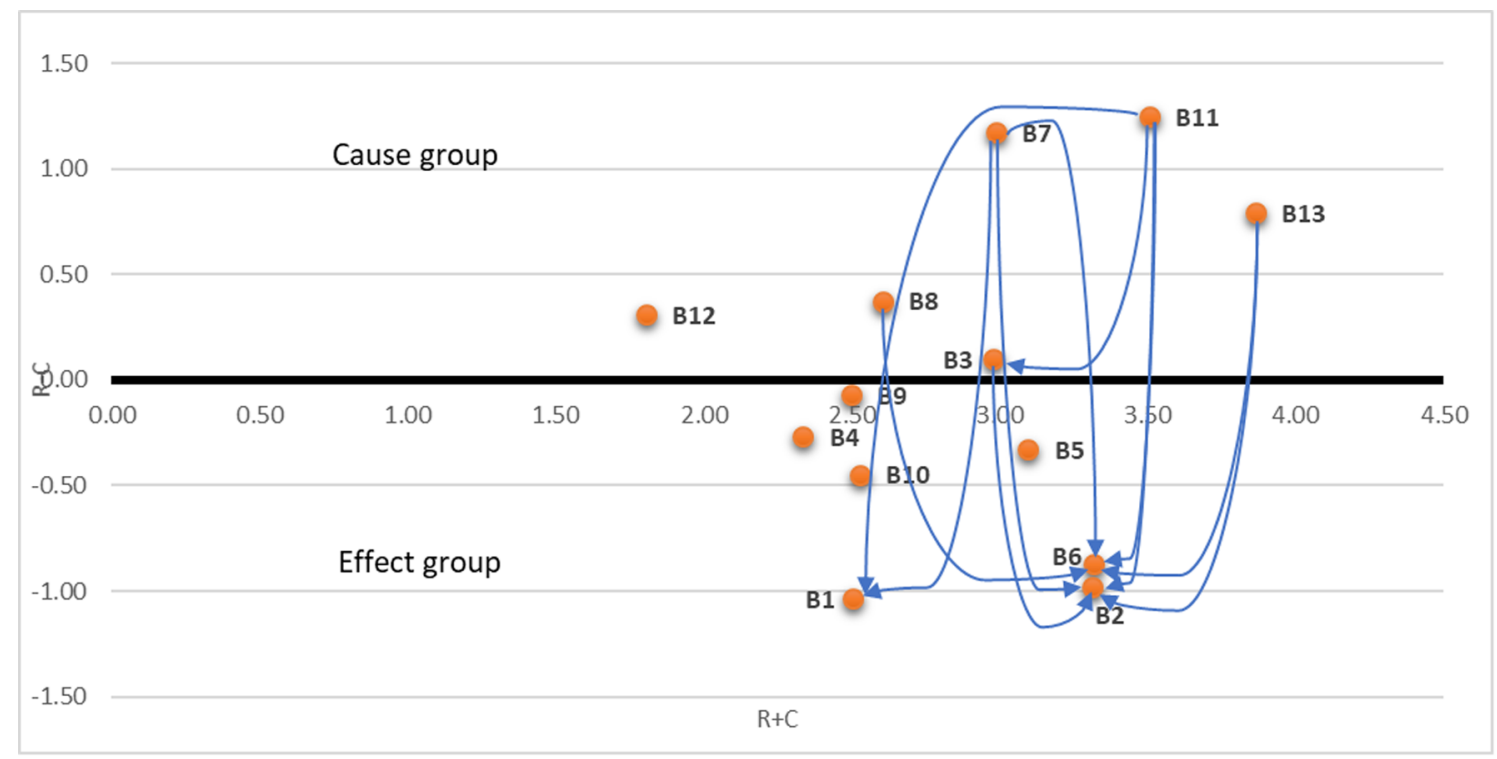

Fig. 2. DEMATEL casual-effect diagram (Technology Provider).

for Blockchain-related technologies are required by the manufacturer and the retailer (technology users); however, technology providers do not consider this to be an issue for them. Moreover, supply chain-based barriers, such as challenge of information disclosure policy between partners in the supply chain (B5) and problems in collaboration, communication and coordination in the supply chain (B6), have only been identified as prominent barriers by supply chain entities (i.e., the manufacturer and retailer).

Furthermore, lack of government policy/regulation guidance and support (B11) and lack of external stakeholder pressure and involvement (B13) are recognized as key cause and prominent barriers by technology providers only. Given the controversies surrounding some Blockchain-based technologies (e.g., cryptocurrencies) the technology providers look forward to clear government policies and regulatory guidance, and support from other external stakeholders to help potential technology users buy-in the Blockchain-based technologies supporting the sustainability cause.

Despite the relative differences, there are some commonalities as well. For example, immaturity of technology (B7) has been identified as the key cause barrier by all three evaluators. However, to our surprise, the key cause and prominent barriers are obviously different from barriers rankings based on the evaluators' importance rankings across the three evaluators (see Tables 3-5). This suggests that the really important barriers, namely the key cause and prominent barriers, are quite different from the ones perceived by the evaluators.

\section{Discussion}

\subsection{Managerial implications for technology providers}

Blockchain-based LCA presents a great business opportunity for technology providers (Zhang et al., 2020). Technology firms need to equip themselves with advanced capabilities in order to unlock the full potential of Blockchain technology and to be able to provide the best solutions to their customers. Similarly, integration of smart, enabling technologies, such as IoT, BDA, cloud computing and data visualization, along with Blockchain technology offers huge potential in advancing new technological solutions (Aryal, Liao, Nattuthurai, \& Li, 2018; Saberi

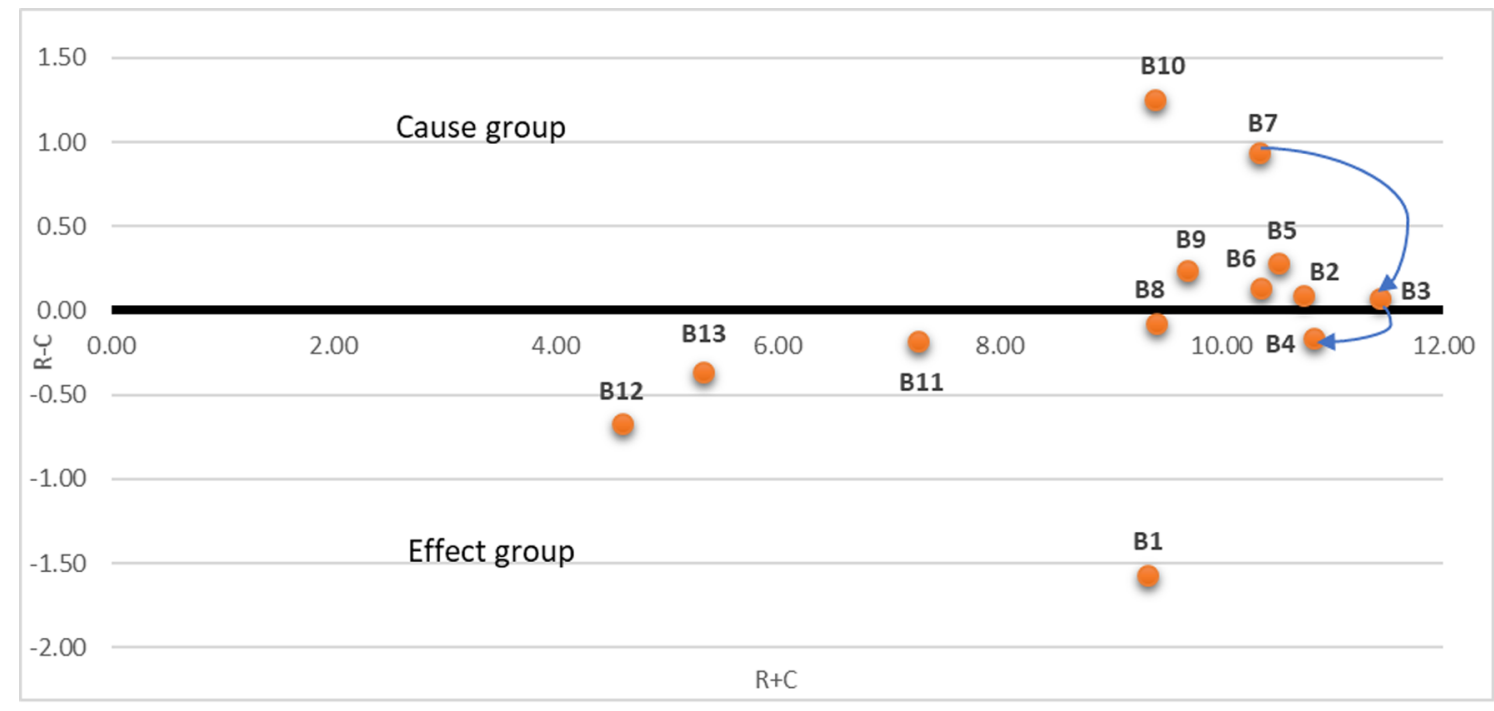

Fig. 3. DEMATEL casual-effect diagram (Manufacturer). 


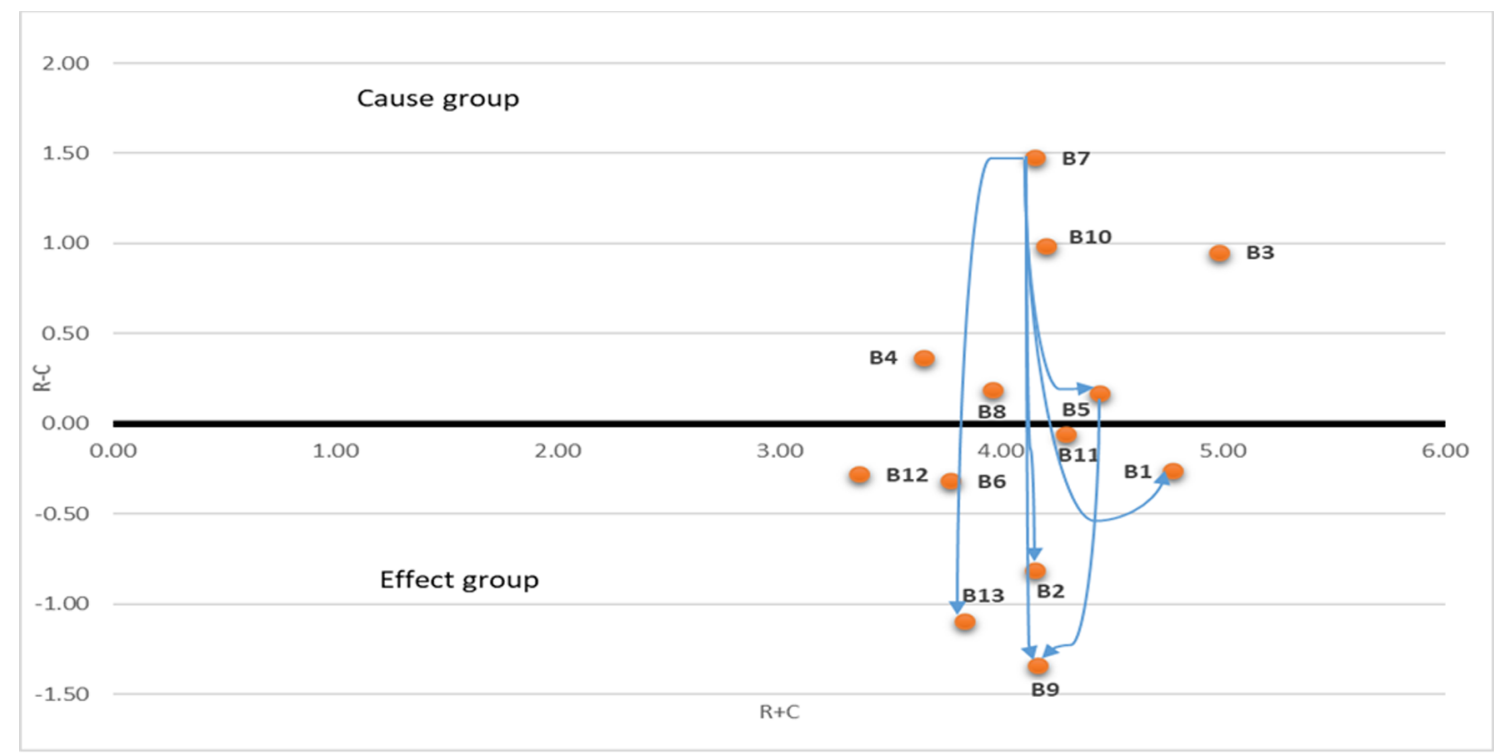

Fig. 4. DEMATEL casual-effect diagram (Retailer).

Table 4

DEMATEL results (Technology Provider).

\begin{tabular}{ccccc}
\hline Barriers & $\mathrm{R}+\mathrm{C}$ & $\mathrm{R}-\mathrm{C}$ & Evaluator's Ranking & DEMATEL Ranking \\
\hline B1 & 2.50 & -1.04 & 11 & 13 \\
B2 & 3.31 & -0.98 & 5 & 12 \\
B3 & 2.98 & 0.10 & 6 & 6 \\
B4 & 2.33 & -0.27 & 9 & 8 \\
B5 & 3.10 & -0.33 & 7 & 9 \\
B6 & 3.32 & -0.87 & 8 & 11 \\
B7 & 2.99 & 1.17 & 4 & 2 \\
B8 & 2.60 & 0.37 & 3 & 4 \\
B9 & 2.50 & -0.07 & 10 & 7 \\
B10 & 2.53 & -0.45 & 12 & 10 \\
B11 & 3.50 & 1.25 & 1 & 5 \\
B12 & 1.81 & 0.31 & 13 & 3 \\
B13 & 3.86 & 0.79 & 2 & \\
\hline
\end{tabular}

Table 5

DEMATEL results (Manufacturer).

\begin{tabular}{ccccc}
\hline Barriers & $\mathrm{R}+\mathrm{C}$ & $\mathrm{R}-\mathrm{C}$ & Evaluator's Ranking & DEMATEL Ranking \\
\hline B1 & 9.34 & -1.57 & 7 & 13 \\
B2 & 10.73 & 0.09 & 5 & 6 \\
B3 & 11.42 & 0.07 & 6 & 7 \\
B4 & 10.83 & -0.16 & 4 & 9 \\
B5 & 10.51 & 0.28 & 2 & 3 \\
B6 & 10.36 & 0.13 & 1 & 5 \\
B7 & 10.35 & 0.94 & 8 & 2 \\
B8 & 9.42 & -0.07 & 9 & 8 \\
B9 & 9.69 & 0.24 & 10 & 4 \\
B10 & 9.40 & 1.26 & 3 & 1 \\
B11 & 7.26 & -0.18 & 11 & 12 \\
B12 & 4.60 & -0.67 & 13 & 11 \\
B13 & 5.32 & -0.37 & 12 & \\
& & & &
\end{tabular}

et al., 2019). However, based on the study results, technology providers consider lack of government policy/regulation guidance and support (B11) as a significant cause barrier to the development of Blockchain-based technological solutions. Our study results are consistent with Mangla et al. (2018) who argue that lack of government policy and support is a significant hurdle for developing supportive technological mechanisms for achieving sustainability. In this regard, adverse policies about Bitcoin issued by several governments have greatly hindered the development of other Blockchain-based solutions (Mougayar, 2016).
Table 6

DEMATEL results (Retailer).

\begin{tabular}{ccccc}
\hline Barriers & $\mathrm{R}+\mathrm{C}$ & $\mathrm{R}-\mathrm{C}$ & Evaluator's Ranking & DEMATEL Ranking \\
\hline B1 & 4.77 & -0.26 & 6 & 8 \\
B2 & 4.15 & -0.81 & 2 & 11 \\
B3 & 4.98 & 0.95 & 3 & 3 \\
B4 & 3.65 & 0.37 & 10 & 4 \\
B5 & 4.45 & 0.17 & 13 & 6 \\
B6 & 3.77 & -0.31 & 7 & 10 \\
B7 & 4.15 & 1.48 & 8 & 1 \\
B8 & 3.96 & 0.19 & 5 & 5 \\
B9 & 4.17 & -1.34 & 4 & 2 \\
B10 & 4.20 & 0.99 & 11 & 7 \\
B11 & 4.29 & -0.06 & 1 & 9 \\
B12 & 3.36 & -0.28 & 12 & 12 \\
B13 & 3.84 & -1.09 & 9 & \\
\hline
\end{tabular}

Moreover, lack of external stakeholder pressure and involvement (B13) is also identified as a significant cause barrier from the technology provider's perspective. This suggests that there is a great need to increase the awareness level of external stakeholders (i.e., governments, regulatory bodies, NGOs, industries, communities etc.) about the potential of Blockchain technology for supporting sustainability and the circular economy (Kouhizadeh, Zhu, \& Sarkis, 2019; Saberi et al., 2019). Online resources, for example, "7 Ways The Blockchain Can Save The Environment and Stop Climate Change" (futurethinkers.org, 2017), can be used as a starting point for promoting Blockchain-based technologies.

Challenges in integrating sustainable practices and Blockchain technology through SCM (B6) and the immaturity of technology (B7) are the next key cause and prominent barriers for technology providers. For such issues, integration of other enabling technologies, such as IoT, BDA and cloud computing with Blockchain technology, are suggested as possible remedies in the extant literature (Aryal et al., 2018; Saberi et al., 2019).

\subsection{Managerial implications for the manufacturer and the retailer (Technology Users)}

Historically, data collection has been recognized as a significant challenge in LCA-based works (Hospido, Davis, Berlin, \& Sonesson, 2010). In a complex system such as supply chains, traditional LCA methodologies fail to account for all possible inputs of a product system (Genovese, Acquaye, Figueroa, \& Koh, 2017). Although Blockchain 
Table 7

Barriers with the highest prominence and net cause-effect values.

\begin{tabular}{|c|c|c|c|c|c|c|}
\hline \multirow[t]{2}{*}{ Barriers Description } & \multicolumn{3}{|c|}{ Most prominent barriers } & \multicolumn{3}{|c|}{ Key cause barriers } \\
\hline & M & $\mathrm{R}$ & $\mathrm{TP}$ & M & $\mathrm{R}$ & TP \\
\hline B1: Hesitation to convert to new systems & & & & & & \\
\hline B2: Lack of management commitment and support & $\checkmark$ & & & & & \\
\hline B3: Lack of new organizational policies for using technology & $\checkmark$ & & & & - & \\
\hline B4: Problems in collaboration, communication and coordination in the supply chain & $\checkmark$ & & & & & \\
\hline B5: Challenge of information disclosure policy between partners in the supply chain & & & & & & \\
\hline B6: Challenges in integrating sustainable practices and Blockchain technology through SCM & & & $\checkmark$ & & & \\
\hline B7: Immaturity of technology & & & & - & - & - \\
\hline \multicolumn{7}{|l|}{ B8: Security challenge } \\
\hline \multicolumn{7}{|l|}{ B9: Doubt about Blockchain technology due to negative public perception } \\
\hline B10: Technical challenges for collecting supply chain data in real time & & & & - & - & \\
\hline B11: Lack of government policy/regulation guidance and support & & & $\checkmark$ & & & - \\
\hline \multicolumn{7}{|l|}{ B12: Lack of a culture of environmental protection } \\
\hline B13: Lack of external stakeholder pressure and involvement & & & $\checkmark$ & & & - \\
\hline
\end{tabular}

*Note: $\mathrm{M}=$ Manufacturer, $\mathrm{R}=$ Retailer, $\mathrm{TP}=$ Technology Provider.

technology offers great potential in overcoming these challenges, the immaturity of technology (B7) and limited number of such applications also lead to concerns over Blockchain's ability to handle the technical challenges for collecting supply chain data in real time (B10). In this regard, there is a greater need to promote the successful applications of Blockchain-based technologies to develop more confidence among potential technology users including manufacturing and retail firms. For example, Toyota, the world's second-largest automotive manufacturer, has implemented Blockchain technology in its internal operations, marketing communications and supply chain networks since 2017 (Kouhizadeh et al., 2019). The Toyota Research Institute aims to enhance its business intelligence, accelerate autonomous driving technology and promote a sharing mobility ecosystem using Blockchain technology (Shieber, 2017). Similarly, Walmart, the world's largest brick-and-mortar retailer, has successfully used Blockchain technology to track pork in China and mangos in the United States (Hyperledger, 2018).

The lack of new organizational policies for using technology (B3) is identified as another major barrier. This barrier is recognized as the key cause barrier (from the retailer's perspective) and has highest prominence value from both the manufacturer and the retailer (technology users) perspective. This implies that the organizations' management need to clarify policies relating to the usage of Blockchain technology in supply chain processes. Moreover, defining new roles and responsibilities and developing expertise to support Blockchain-enabled LCA will also be required (Mendling et al., 2018). This applies to both the manufacturer and the retailer.

Overall, the three barriers discussed here, namely, B10, B7 and B3, have a significant influence on B1, B2, B4, B5, B9, B11 and B13 from both the manufacturer and the retailer (technology users) perspective. This suggests that well designed/developed Blockchain applications and clear organizational policies on technology usage offer great promise to both manufacturers and retailers in conducting accurate assessments of environmental impacts of their product systems using Blockchain-based LCA. With the Blockchain-enabled data traceability and transparency, firms can build superior customer trust and loyalty resulting in increased sales and better market performance (Zhang et al., 2020).

\section{Conclusions}

Life cycle thinking has been gaining increasing importance in addressing the sustainability-related challenges within supply chains. In this regard, LCA has been widely used for the assessment of environmental impacts of the product systems; however, traditional LCA methodologies have various limitations. Blockchain technology offers great potential in overcoming these limitations but its adoption is impeded by various barriers. This study aims to identify and prioritize the barriers to Blockchain-based LCA.

This paper makes several original contributions. Firstly, it is among the pioneering works on Blockchain-based LCA. Although Blockchain technologies have been receiving increased attention due to their potential in improving efficiency and effectiveness of the imbedded systems, there are several barriers affecting the adoption of Blockchainbased systems in different application areas, for example, LCA. Secondly, to the best of our knowledge, this is the first study to systematically investigate and prioritize barriers to Blockchain adoption in LCA. Thirdly, viewpoints of three representative organizations from China (study evaluators) with Blockchain implementation experiences were considered. The results show that the key cause and most prominent barriers for technology providers include immaturity of technology, lack of government policy/regulation guidance and support, lack of external stakeholder pressure and involvement and challenges in integrating sustainable practices and Blockchain technology through SCM; however, for technology users the key cause and most prominent barriers include lack of new organizational policies for using technology, immaturity of technology, technical challenges for collecting supply chain data in real time, hesitation to convert to new systems, lack of management commitment and support, lack of new organizational policies for using technology, problems in collaboration, communication and coordination in the supply chain and challenge of information disclosure policy between partners in the supply chain. Finally, the managerial implications based on the results and findings provide great support in decision making to technology providers as well as to technology users (manufacturers and retailers).

Despite several contributions, this study has its limitations. Given the infancy of Blockchain technology interventions in supply chain research and practice, the analysis presented in this research was based upon the results from three of the most representative evaluators with Blockchain implementation experience. Future researchers may consider a larger scale in terms of number of respondents as well as research including other internal (e.g., suppliers) and external (e.g., government/regulatory bodies) stakeholders. Future research may also consider different contexts (i.e., other than China) to explore more insights which would help us to understand the dynamics of Blockchain technology adoption in different contexts.

\section{Acknowledgement}

This work was supported by the National Natural Science Foundation of China under Grant [51405089]; National Science Foundation of Guangdong Province under [2018A0303130035]. 
Appendix A. Profile of DEMATEL study participants

\begin{tabular}{|c|c|c|c|c|}
\hline Participant Number & Role/Industry type & Organization's annual revenue & Position of participant & Work experiences \\
\hline P1 & Technology provider & $¥ 300,000,000+$ & Head of Blockchain research \& development & 8 years \\
\hline P2 & Manufacturing (control equipment) & $¥ 700,000,000+$ & Vice President & 27 years \\
\hline P3 & Retail (pharmaceutical products) & $¥ 200,000,000+$ & General Manager & 13 years \\
\hline
\end{tabular}

Appendix B. Total relation matrix (Technology Provider)

\begin{tabular}{|c|c|c|c|c|c|c|c|c|c|c|c|c|c|}
\hline Barrier & B1 & B2 & B3 & B4 & B5 & B6 & B7 & B8 & B9 & B10 & B11 & B12 & B13 \\
\hline B1 & 0.04 & 0.12 & 0.04 & 0.08 & 0.05 & 0.10 & 0.02 & 0.07 & 0.04 & 0.09 & 0.03 & 0.02 & 0.04 \\
\hline B2 & 0.14 & 0.09 & 0.06 & 0.05 & 0.14 & 0.17 & 0.06 & 0.04 & 0.12 & 0.11 & 0.05 & 0.03 & 0.11 \\
\hline B3 & 0.19 & 0.20 & 0.07 & 0.11 & 0.09 & 0.16 & 0.10 & 0.11 & 0.12 & 0.13 & 0.10 & 0.04 & 0.13 \\
\hline B4 & 0.11 & 0.12 & 0.12 & 0.05 & 0.13 & 0.15 & 0.03 & 0.04 & 0.05 & 0.06 & 0.04 & 0.03 & 0.10 \\
\hline B5 & 0.13 & 0.17 & 0.11 & 0.14 & 0.08 & 0.17 & 0.05 & 0.10 & 0.06 & 0.12 & 0.10 & 0.04 & 0.12 \\
\hline B6 & 0.08 & 0.13 & 0.11 & 0.10 & 0.12 & 0.09 & 0.04 & 0.05 & 0.10 & 0.11 & 0.10 & 0.08 & 0.11 \\
\hline B7 & 0.22 & 0.24 & 0.17 & 0.14 & 0.16 & 0.22 & 0.07 & 0.17 & 0.16 & 0.18 & 0.12 & 0.05 & 0.18 \\
\hline B8 & 0.13 & 0.18 & 0.09 & 0.14 & 0.18 & 0.20 & 0.07 & 0.05 & 0.11 & 0.12 & 0.06 & 0.04 & 0.12 \\
\hline B9 & 0.15 & 0.16 & 0.10 & 0.06 & 0.11 & 0.13 & 0.04 & 0.05 & 0.06 & 0.11 & 0.09 & 0.04 & 0.11 \\
\hline B10 & 0.11 & 0.13 & 0.10 & 0.05 & 0.08 & 0.10 & 0.08 & 0.05 & 0.07 & 0.06 & 0.07 & 0.05 & 0.10 \\
\hline B11 & 0.21 & 0.24 & 0.20 & 0.15 & 0.21 & 0.24 & 0.14 & 0.18 & 0.19 & 0.17 & 0.09 & 0.15 & 0.19 \\
\hline B12 & 0.09 & 0.10 & 0.10 & 0.05 & 0.13 & 0.12 & 0.04 & 0.05 & 0.05 & 0.06 & 0.12 & 0.04 & 0.10 \\
\hline B13 & 0.18 & 0.26 & 0.16 & 0.17 & 0.23 & 0.25 & 0.16 & 0.16 & 0.15 & 0.19 & 0.16 & 0.13 & 0.12 \\
\hline
\end{tabular}

Significant relationships $(\varnothing=\mathbf{0 . 1 9})$ : B7-B1, B11-B1, B3-B2, B7-B2, B11-B2, B13-B2, B11-B3, B7-B6, B8-B6, B11-B6, B13-B6.

Appendix C. Total relation matrix (Manufacturer)

\begin{tabular}{|c|c|c|c|c|c|c|c|c|c|c|c|c|c|}
\hline Barrier & B1 & B2 & B3 & B4 & B5 & B6 & B7 & B8 & B9 & B10 & B11 & B12 & B13 \\
\hline B1 & 0.31 & 0.37 & 0.39 & 0.40 & 0.36 & 0.36 & 0.31 & 0.29 & 0.29 & 0.28 & 0.23 & 0.15 & 0.16 \\
\hline B2 & 0.49 & 0.41 & 0.53 & 0.51 & 0.46 & 0.48 & 0.43 & 0.43 & 0.43 & 0.36 & 0.36 & 0.25 & 0.26 \\
\hline B3 & 0.52 & 0.52 & 0.46 & 0.54 & 0.51 & 0.51 & 0.48 & 0.46 & 0.46 & 0.40 & 0.37 & 0.26 & 0.25 \\
\hline B4 & 0.51 & 0.47 & 0.50 & 0.42 & 0.48 & 0.48 & 0.43 & 0.43 & 0.43 & 0.38 & 0.33 & 0.25 & 0.24 \\
\hline B5 & 0.51 & 0.48 & 0.53 & 0.52 & 0.40 & 0.49 & 0.43 & 0.44 & 0.43 & 0.38 & 0.33 & 0.22 & 0.24 \\
\hline B6 & 0.50 & 0.49 & 0.51 & 0.50 & 0.46 & 0.39 & 0.42 & 0.42 & 0.42 & 0.35 & 0.32 & 0.22 & 0.23 \\
\hline B7 & 0.53 & 0.51 & 0.54 & 0.51 & 0.48 & 0.48 & 0.38 & 0.45 & 0.47 & 0.40 & 0.34 & 0.26 & 0.30 \\
\hline B8 & 0.43 & 0.42 & 0.45 & 0.44 & 0.41 & 0.39 & 0.38 & 0.32 & 0.38 & 0.32 & 0.29 & 0.20 & 0.24 \\
\hline B9 & 0.46 & 0.45 & 0.49 & 0.46 & 0.43 & 0.43 & 0.40 & 0.41 & 0.33 & 0.34 & 0.31 & 0.21 & 0.25 \\
\hline B10 & 0.50 & 0.47 & 0.50 & 0.49 & 0.46 & 0.46 & 0.43 & 0.45 & 0.45 & 0.31 & 0.33 & 0.22 & 0.26 \\
\hline B11 & 0.32 & 0.31 & 0.37 & 0.32 & 0.30 & 0.28 & 0.26 & 0.31 & 0.26 & 0.23 & 0.19 & 0.21 & 0.19 \\
\hline B12 & 0.17 & 0.17 & 0.18 & 0.18 & 0.16 & 0.16 & 0.15 & 0.15 & 0.15 & 0.14 & 0.13 & 0.08 & 0.13 \\
\hline B13 & 0.21 & 0.23 & 0.22 & 0.22 & 0.20 & 0.20 & 0.19 & 0.19 & 0.21 & 0.19 & 0.18 & 0.12 & 0.10 \\
\hline
\end{tabular}

Significant relationships $(\emptyset=0.53)$ : B3-B4, B7-B3.

Appendix D. Total relation matrix (Retailer)

\begin{tabular}{|c|c|c|c|c|c|c|c|c|c|c|c|c|c|}
\hline Barrier & B1 & B2 & B3 & B4 & B5 & B6 & B7 & B8 & B9 & B10 & B11 & B12 & B13 \\
\hline B1 & 0.15 & 0.22 & 0.17 & 0.15 & 0.15 & 0.17 & 0.10 & 0.13 & 0.23 & 0.17 & 0.22 & 0.15 & 0.24 \\
\hline B2 & 0.20 & 0.11 & 0.14 & 0.08 & 0.12 & 0.11 & 0.06 & 0.10 & 0.17 & 0.10 & 0.18 & 0.13 & 0.19 \\
\hline B3 & 0.26 & 0.26 & 0.16 & 0.20 & 0.26 & 0.21 & 0.13 & 0.22 & 0.29 & 0.22 & 0.26 & 0.22 & 0.28 \\
\hline B4 & 0.23 & 0.18 & 0.20 & 0.09 & 0.18 & 0.18 & 0.10 & 0.15 & 0.19 & 0.12 & 0.12 & 0.11 & 0.16 \\
\hline B5 & 0.16 & 0.17 & 0.17 & 0.12 & 0.13 & 0.22 & 0.18 & 0.21 & 0.26 & 0.15 & 0.18 & 0.19 & 0.17 \\
\hline B6 & 0.19 & 0.16 & 0.14 & 0.13 & 0.12 & 0.09 & 0.11 & 0.13 & 0.15 & 0.10 & 0.11 & 0.16 & 0.13 \\
\hline B7 & 0.28 & 0.28 & 0.24 & 0.19 & 0.25 & 0.23 & 0.10 & 0.22 & 0.27 & 0.17 & 0.19 & 0.14 & 0.26 \\
\hline B8 & 0.21 & 0.21 & 0.13 & 0.09 & 0.14 & 0.18 & 0.07 & 0.10 & 0.24 & 0.13 & 0.22 & 0.18 & 0.19 \\
\hline B9 & 0.14 & 0.14 & 0.09 & 0.06 & 0.12 & 0.08 & 0.05 & 0.11 & 0.10 & 0.06 & 0.14 & 0.12 & 0.19 \\
\hline B10 & 0.25 & 0.22 & 0.19 & 0.20 & 0.24 & 0.19 & 0.19 & 0.21 & 0.28 & 0.11 & 0.17 & 0.13 & 0.22 \\
\hline B11 & 0.19 & 0.21 & 0.18 & 0.14 & 0.19 & 0.16 & 0.10 & 0.13 & 0.22 & 0.09 & 0.12 & 0.15 & 0.23 \\
\hline B12 & 0.13 & 0.15 & 0.11 & 0.12 & 0.14 & 0.11 & 0.08 & 0.10 & 0.19 & 0.11 & 0.14 & 0.08 & 0.10 \\
\hline B13 & 0.14 & 0.16 & 0.10 & 0.08 & 0.10 & 0.12 & 0.07 & 0.07 & 0.15 & 0.08 & 0.13 & 0.07 & 0.10 \\
\hline
\end{tabular}

Significant relationships $(\emptyset=\mathbf{0 . 2 4})$ : B3-B1, B7-B1, B10-B1, B3-B2, B7-B2, B3-B5, B7-B5, B3-B9, B5-B9, B7-B9, B10-B9, B3-B11, B3-13, B7-B13. 


\section{References}

Alam-Tabriz, A., Rajabani, N., \& Farrokh, M. (2014). An integrated fuzzy DEMATEL-ANP-TOPSIS methodology for supplier selection problem. Global Journal of Management Studies and Researches, 1(2), 85-99.

Aryal, A., Liao, Y., Nattuthurai, P., \& Li, B. (2018). The emerging big data analytics and IoT in supply chain management: A systematic review. Supply Chain Management: An International Journal.

Awasthi, A., \& Grzybowska, K. (2014). Barriers of the supply chain integration process. In P. Golinska (Ed.). Logistics Operations, Supply Chain Management and Sustainability (pp. 15-30). Springer.

Bahadori, M., Ravangard, R., \& Asghari, B. (2013). Perceived Barriers affecting access to preventive dental services: Application of DEMATEL method. Iranian Red Crescent Medical Journal, 15(8), 655-662.

Büyüközkan, G., \& Çifçi, G. (2012). A novel hybrid MCDM approach based on fuzzy DEMATEL, fuzzy ANP and fuzzy TOPSIS to evaluate green suppliers. Expert Systems with Applications, 39(3), 3000-3011.

Carter, C. R., \& Liane Easton, P. (2011). Sustainable supply chain management: Evolution and future directions. International Journal of Physical Distribution \& Logistics Management, 41(1), 46-62.

Deng, H. (1999). Multicriteria analysis with fuzzy pairwise comparison. International Journal of Approximate Reasoning, 21(3), 215-231.

Dou, Y., \& Sarkis, J. (2013). A multiple stakeholder perspective on barriers to implementing China RoHS regulations. Resources, Conservation and Recycling, 81, 92-104.

Dou, Y., Sarkis, J., \& Bai, C. (2014). Government green procurement: A fuzzy-DEMATEL analysis of barriers. In C. Kahraman, \& B. Öztayși (Eds.). Supply Chain Management Under Fuzziness: Recent Developments and Techniques (pp. 567-589). Berlin, Heidelberg: Springer, Berlin Heidelberg.

Farooque, M., Zhang, A., \& Liu, Y. (2019). Barriers to circular food supply chains in China. Supply Chain Management: An International Journal, 24(5), 677-696.

Farooque, M., Zhang, A., Thürer, M., Qu, T., \& Huisingh, D. (2019). Circular supply chain management: A definition and structured literature review. Journal of Cleaner Production, 228, 882-900.

Finnveden, G., Hauschild, M. Z., Ekvall, T., Guinée, J., Heijungs, R., Hellweg, S., ... Suh, S. (2009). Recent developments in Life Cycle Assessment. Journal of Environmental Management, 91(1), 1-21.

Fontela, E. \& Gabus, A. (1976). The DEMATEL observer, DEMATEL 1976 report. Switzerland, Geneva, Battelle Geneva Research Center.

futurethinkers.org. (2017). 7 Ways The Blockchain Can Save The Environment and Stop Climate Change. https://futurethinkers.org/blockchain-environment-climatechange/. (Accessed 22 April 2019).

Genovese, A., Acquaye, A. A., Figueroa, A., \& Koh, S. C. L. (2017). Sustainable supply chain management and the transition towards a circular economy: Evidence and some applications. Omega, 66(Part B), 344-357.

Guinée, J. B., Heijungs, R., Huppes, G., Zamagni, A., Masoni, P., Buonamici, R., ... Rydberg, T. (2011). Life cycle assessment: Past, present, and future. Environmental Science \& Technology, 45(1), 90-96.

Herrera-Viedma, E. (2015). Fuzzy sets and fuzzy logic in multi-criteria decision making. The 50th anniversary of Prof. Lotfi Zadeh's theory: Introduction. Technological and Economic Development of Economy, 21(5), 677-683.

Hospido, A., Davis, J., Berlin, J., \& Sonesson, U. (2010). A review of methodological issues affecting LCA of novel food products. The International Journal of Life Cycle Assessment, 15(1), 44-52.

Hyperledger. (2018). How Walmart brought unprecedented transparency to the food supply chain with Hyperledger Fabric. https://www.hyperledger.org/wp-content/ uploads/2019/02/Hyperledger_CaseStudy_Walmart_Printable_V4.pdf. (Accessed 16 May 2019).

Kouhizadeh, M., Zhu, Q., \& Sarkis, J. (2019). Blockchain and the circular economy: Potential tensions and critical reflections from practice. Production Planning \& Control, $1-17$.

Krishna, I. M., Manickam, V., Shah, A., \& Davergave, N. (2017). Environmental management: science and engineering for industry. Butterworth-Heinemann.

Kumar, A., \& Dixit, G. (2018). An analysis of barriers affecting the implementation of ewaste management practices in India: A novel ISM-DEMATEL approach. Sustainable Production and Consumption, 14, 36-52.

Li, C.-W., \& Tzeng, G.-H. (2009). Identification of a threshold value for the DEMATEL method using the maximum mean de-entropy algorithm to find critical services provided by a semiconductor intellectual property mall. Expert Systems with
Applications, 36(6), 9891-9898.

Lin, R.-J. (2013). Using fuzzy DEMATEL to evaluate the green supply chain management practices. Journal of Cleaner Production, 40(Supplement C), 32-39.

Liu, X. L., Wang, W. M., Guo, H., Barenji, A. V., Li, Z., \& Huang, G. Q. (2020). Industrial blockchain based framework for product lifecycle management in industry 4.0. Robotics and Computer-Integrated Manufacturing, 63, 101897.

Mangla, S. K., Luthra, S., Mishra, N., Singh, A., Rana, N. P., Dora, M., \& Dwivedi, Y. (2018). Barriers to effective circular supply chain management in a developing country context. Production Planning \& Control, 29(6), 551-569.

Mendling, J., Weber, I., Aalst, W. V. D., Brocke, J. V., Cabanillas, C., Daniel, F., ... Rosa, M. L. (2018). Blockchains for Business Process Management - Challenges and Opportunities. ACM Transactions on Management Information Systems, 9(1), 1-16.

Mettler, M. (2016). Blockchain technology in healthcare: The revolution starts here. 2016 IEEE 18th International Conference on e-Health Networking, Applications and Services (Healthcom) (pp. 1-3). .

Mougayar, W. (2016). The business blockchain: Promise, practice, and application of the next Internet technology. John Wiley \& Sons.

$\emptyset$ lnes, S., Ubacht, J., \& Janssen, M. (2017). Blockchain in government: Benefits and implications of distributed ledger technology for information sharing. Government Information Quarterly, 34(3), 355-364.

Pennington, D. W., Potting, J., Finnveden, G., Lindeijer, E., Jolliet, O., Rydberg, T., \& Rebitzer, G. (2004). Life cycle assessment Part 2: Current impact assessment practice. Environment International, 30(5), 721-739.

Rebitzer, G., Ekvall, T., Frischknecht, R., Hunkeler, D., Norris, G., Rydberg, T., ... Pennington, D. W. (2004). Life cycle assessment: Part 1: Framework, goal and scope definition, inventory analysis, and applications. Environment International, 30(5), 701-720.

Saberi, S., Kouhizadeh, M., Sarkis, J., \& Shen, L. (2019). Blockchain technology and its relationships to sustainable supply chain management. International Journal of Production Research, 57(7), 2117-2135.

Schmidt, W.-P., \& Sullivan, J. (2002). Weighting in Life Cycle assessments in a global context. The International Journal of Life Cycle Assessment, 7(1), 5.

Seçme, N. Y., Bayrakdaroğlu, A., \& Kahraman, C. (2009). Fuzzy performance evaluation in Turkish Banking Sector using Analytic Hierarchy Process and TOPSIS. Expert Systems with Applications, 36(9), 11699-11709.

Shieber, J. (2017). Toyota pushes into blockchain tech to enable the next generation of cars. https://techcrunch.com/2017/05/22/toyota-pushes-into-blockchain-tech-toenable-the-next-generation-of-cars/. (Accessed 10/12/2019.

Venkatesh, V. G., Zhang, A., Luthra, S., Dubey, R., Subramanian, N., \& Mangla, S. (2017). Barriers to coastal shipping development: An Indian perspective. Transportation Research Part D: Transport and Environment, 52, 362-378.

Walter Klöpffer, C. A. U., \& Rebitzer, G. (2000). A report on LCA activities at the SETAC - Third World Congress, 21-25 May 2000 in Brighton, UK. The International Journal of Life Cycle Assessment, 5(4) 249-249.

Weidema, B. P., Thrane, M., Christensen, P., Schmidt, J., \& Løkke, S. (2008). Carbon Footprint. Journal of Industrial Ecology, 12(1), 3-6.

Wernick, I. K., \& Ausubel, J. H. (1997). Industrial ecology: Some directions for research. Program for the Human Environment.

Wu, K.-J., Liao, C.-J., Tseng, M.-L., \& Chiu, A. S. F. (2015). Exploring decisive factors in green supply chain practices under uncertainty. International Journal of Production Economics, 159, 147-157.

Wu, W.-W. (2012). Segmenting critical factors for successful knowledge management implementation using the fuzzy DEMATEL method. Applied Soft Computing, 12(1), 527-535.

Wu, W.-W., \& Lee, Y.-T. (2007). Developing global managers' competencies using the fuzzy DEMATEL method. Expert Systems with Applications, 32(2), 499-507.

Xia, X., Govindan, K., \& Zhu, Q. (2015). Analyzing internal barriers for automotive parts remanufacturers in China using grey-DEMATEL approach. Journal of Cleaner Production, 87, 811-825.

Zhang, A., Venkatesh, V. G., Liu, Y., Wan, M., Qu, T., \& Huisingh, D. (2019). Barriers to smart waste management for a circular economy in China. Journal of Cleaner Production, 240, 118198.

Zhang, A., Zhong, R. Y., Farooque, M., Kang, K., \& Venkatesh, V. G. (2020). Blockchainbased life cycle assessment: An implementation framework and system architecture. Resources, Conservation and Recycling, 152, 104512.

Zhu, Q., Sarkis, J., \& Lai, K.-H. (2015). Reprint of "Supply chain-based barriers for truckengine remanufacturing in China". Transportation Research Part E: Logistics and Transportation Review, 74, 94-108. 